\title{
ETA y el Nacionalismo Vasco en la Transición. Análisis del tratamiento periodístico de la organización ETA en un periódico nacionalista vasco: Deia*
}

\author{
MacaRio HeRnández Nieto
}

\begin{abstract}
ETA and the Basque nationalism during the Spanis transition to democracy. An analysis of the discourse about ETA in a basque nationalism newspaper: Deia
\end{abstract}

\begin{abstract}
RESUMEN
Durante la Transición una parte importante de la sociedad vasca tuvo una postura claramente favorable a la violencia de ETA. Por una parte el abertzlismo radical que expresamente defendia la actividad de esta organización, por otra, el nacionalismo moderado cuyo referente era el Partido Nacionalista Vasco (PNV) y su medio de expresión, el periódico Deia. En este sector social se da

la paradoja de que se condenaban los atentados $y$ al mismo tiempo se mantenia una actitud de comprension hacia los miembros y la actividad de ETA. EI análisis del tratamiento periodístico de Deia documenta esta paradójica posición del nacionalismo vasco moderado que resulta favorable a la organización ETA.
\end{abstract}

PALABRAS CLAVE:

Transición, Nacionalismo Vasco, ETA, Deia, Prensa, Terrorismo.

\begin{abstract}
During the Transition an important part of the Basque society clearly supported ETA's violence. On the one hand, the radical abertzalismo, which openly defended the activities of this organisation. On the other hand, the moderate nationalism, whose referent was the Basque Nationalist Party (PNV) and its supporting media, Deia newspaper. There is a paradox in the attitude of this social group since they condemned the terrorist attacks but at the same time they had a sympathetic attitude towards ETA's members and activities. The analysis of the journalistic treatment by Deia provides evidence of this paradoxical position of the moderate Basque nationalism in favour of ETA.
\end{abstract}

KEYWORDS:

Transition, Basque Nationalism, ETA, Deia, Press, Terrorism.

* Este artículo es una síntesis del trabajo de investigación inédito dirigido por la profesora Susana Sueiro y presentado en el Departamento de Historia Contemporánea, ETA y el nacionalismo vasco en la Transición. Análisis del tratamiento periodístico de la Organización ETA en un periódico nacionalista vasco: Deia. (Madrid, UNED, 2005). 
Existían razones para la esperanza. Había indicios de una posible reconversión del franquismo en un sistema democrático. Es más, estos indicios se convertían en pruebas del nacimiento de la democracia tras la celebración de las elecciones generales del 15 de junio de 1977. En Euskadi, los que clamaban por la autonomía recibían con la creación del Consejo General Vasco las primeras muestras de que iba a ser posible hacer realidad el autogobierno añorado. La Constitución que se elaboraba podía suponer la institucionalización de su autonomía. La amnistía, por fin, se hacia realidad. Y, sin embargo, ETA iniciaba entonces la escalada criminal más mortífera de su historia'. Para explicar esta aparente contradicción se puede acudir a diferentes razones de orden interno de la organización terrorista. Pero teniendo en cuenta que un grupo terrorista tiene más fuerza y ánimo para mantener su actividad cuanto mayor apoyo encuentre en la sociedad, tenemos que preguntarnos quién apoyaba a ETA en estos momentos de criminal euforia. Es obvio que los grupos radicales de la izquierda abertzale en torno a la palabra apologética del diario Egin y el semanal Punto y Hora le eran incondicionales. También es claro que parte importante de las bases del PNV mostraban una actitud proclive a no condenar la actividad de ETA ${ }^{2}$. Pero, ¿cuál era la postura frente a ETA del nacionalismo vasco moderado cuyo referente político era el PNV? En aquellos momentos de la Transición las manifestaciones oficiales del PNV fueron de condena. No obstante, ciertas opiniones y actitudes del entorno del nacionalismo moderado vasco presentan visos de que una parte importante de la sociedad vasca nacionalista, si no alaba la actividad de ETA, sí la comprende y la disculpa, lo que favorece el entusiasmo criminal de ETA, tal vez sin pretenderlo.

Esta es la conclusión del análisis del diario Deia cuya síntesis se expone a continuación. Pero aclaremos de paso que acudir a la prensa para investigar un hecho histórico no debe resultar extraño, pues la prensa como información sobre los hechos y sobre las opiniones y manifestaciones de agentes históricos es una fuente de investigación importante de la historia contemporánea y, sobre todo, de la "historia del presente". Por otra parte si al estudio de lo publicado en las páginas de un periódico añadimos un análisis periodístico (en busca de "cómo se dice lo que se dice"), los resultados pueden ser sorprendentes para acercarnos a la comprensión de un acontecimiento histórico. Un estudio del periódico en el que no sólo se tenga en cuenta lo que se publica sino que además se indague en las técnicas periodísticas utilizadas para transmitir mensajes y opiniones -a veces de modo subliminal- puede resultar de enorme valor a la hora de descubrir las opiniones e intereses del grupo que controla dicho periódico y de la parte de la sociedad a la que se dirige pretendiendo transmitirle unas opiniones o (razones de mercado) adaptarse al estado de opinión que sus lectores ya tienen. Por eso no se puede dudar del interés desde la investigación histórica del estudio de la prensa

1 Los tres años de mayor número de personas asesinadas por ETA han sido 1978, año que comprende este trabajo de investigación, con 69 asesinatos; 1979 , con 83, y 1980, con 99.

2 Se quejaban a la dirección del Partido de que con estas condenas "se hacía el juego al Gobiemo"; ver Santiago de Pablo y otros, El Péndulo patriótico, Barcelona, Crítica, 2001 p. 332. 
como sujeto histórico que influye (a veces de modo decisivo) en el acontecer histórico. Estos motivos nos han llevado a elegir Deia como objeto y fuente de esta investigación. También esta elección se debe al carácter de órgano de expresión del PNV ( $y$ del nacionalismo moderado en general) que asumió apenas pasaron los primeros meses desde su aparición ${ }^{3}$.

\section{LOS MEDIOS DE COMUNICACIÓN Y EL TERRORISMO`}

Si aceptamos la definición del reconocido analista del terrorismo Brian M. Jenkins de terrorismo como teatro, los medios de difusión no serán el personaje central - papel que sin duda hay que otorgar a la acción terrorista- pero tendrán un papel secundario de enorme relevancia en el drama que se representa. Porque el terrorismo es violencia, pero, "es una violencia que procura hacerse notar por la gente ${ }^{5}$. Es en esta faceta fundamental del terrorismo donde la prensa se hace imprescindible. Proporciona «un lazo esencial entre las figuras principales del drama, los terroristas y sus víctimas, $y$ la audiencia que pretenden tener ${ }^{6}$. A este respecto son significativas las declaraciones de Bommi Blandlan al diario «Stern» el 1 de junio de 1978: «sin reportajes periodísticos nos encontramos ante un cierto vacío, nuestra causa se sostiene en cierta medida gracias a la prensa» ${ }^{7}$. Esta necesidad de publicidad es imprescindible porque la organización terrorista que defiende un proyecto político buscará en los medios de comunicación conseguir no sólo intimidar, sino también aumentar adeptos y apoyos sociales a su causa. De ahi el hecho de que a cada acción terrorista le siga un comunicado en el cual, a la vez que se justifica la acción, se recuerda su programa político. En una sociedad democrática de libertad de expresión y de mercado, el papel de los medios de comunicación es imprescindible para que el terrorismo exista. Walter Laqueur dice: «El éxito de una operación terrorista depende casi por completo de la cantidad de publicidad que reciba»"

Pero aunque los medios de comunicación sean imprescindibles para el terrorismo, no podemos pedir que éstos enmudezcan. En este sentido se expresa el es-

${ }^{3}$ En los primeros pasos de este periódico, su dirección huye de ser identificada directamente con el PNV, aunque fueron gentes de este partido los fundadores de este diario, pero esta no fue la tónica de futuro. Apenas habia pasado medio año cuando la tendencia a identificarse con el mundo nacionalista se hace cada vez más acusada. Ver para este tema BezUnAatea, O., Noticias e ideología profesional. Prensa vasca en la Transición política. Bilbao, Ed. Deusto, 1988.

${ }_{4}^{4}$ Parece oportuno hacer algunas reflexiones basadas en la obra de importantes teóricos de la relación prensa- terrorismo, conducentes a mostrar las líneas que han servido de entramado al análisis de Deia. Estas líneas son las características del tratamiento del terrorismo por la prensa del llamado «Tratamiento Limitado".

5 JeNkINS, BriAn, M., citado en Pedro ORIVE RIVA, «Los Medios de Comunicación y Terrorismo", Jornadas de Estudio "El Terrorismo y los Medios de Comunicación Social desde el punto de vista de la Defensa", Madrid, CESEDEN, 1980, p. 38.

- JeNkINS, Brian M.: «El Terrorismo y los medios informativos", Terrorismo y Medios de Comunicación social, Madrid. Ministerio de Interior, 1984, p. 52.

7 BENEGAS, J. M. .": "El Caso de España", Terrorismo y Medios de Comunicación social, cit., p. 155. 
critor y periodista Gaspare Barbiellini Amidei: «todos estamos bien enterados de que los medios informativos son un eco formidable para el terrorismo. Sabemos que el terrorismo, de algún modo, nos utiliza como medio propagandístico de segundo grado. Su medio de primer grado es el acto terrorista en sí. Esto es suficientemente evidente. Solamente [...] el silencio de la prensa [...] puede eliminar completamente este arma de los terroristas. Nos enfrentamos con dos necesidades: destruir el terrorismo sin destruir al mismo tiempo la sociedad o la libertad de prensa" ${ }^{9}$. No es posible que en una sociedad democrática calle la prensa. La propuesta del silencio de que habla un experto historiador de temas policiales como Vidal Martín Turrado ${ }^{10}$, no cuenta hoy con clara aceptación en una sociedad democrática e, incluso, se la considera peligrosa y hasta contraproducente pues esto podría instigar a los terroristas a llevar a cabo acciones más luctuosas y espectaculares.

La prensa, por tanto, debe informar sobre el terrorismo, debe tener informada a la sociedad de todo lo que ocurre y le afecta. Pero esta información puede hacerse desde la perspectiva de los terroristas, que casi siempre sería apología, o desde el campo de las víctimas y la sociedad que lo sufren. Una tercera vía, que no es válida en una sociedad democrática, es la que podemos denominar del "periodismo neutral". Es un tratamiento del terrorismo que no discrimina las noticias relacionadas con él en lo referente a la búsqueda de la primicia, primeras páginas, titulares y ubicación en tanto en cuanto son más relevantes las acciones y la propia organización terrorista. Este tratamiento se fundamenta en la libertad de expresión sin limitación alguna y tiene como consecuencia la coincidencia con los intereses publicitarios de la organización terrorista que consigue de este modo ser a diario protagonista, transmitiendo información a los ciudadanos a través de la prensa ${ }^{11}$. En definitiva, la mayoria de quienes opinan sobre este asunto están de acuerdo en que hay que evitar el silencio sobre el terrorismo pero procurando que la información no beneficie al propio terrorismo. Ciertamente no es fácil conjugar la libertad de expresión y el derecho de información con el generalizado deseo de los profesionales de los medios de evitar las ventajas que el terrorismo consigue con la información publicada. Pero a pesar de la dificultad es posible no favorecer los intereses de los terroristas si se ofrece una información objetiva y veraz. "Lo que se debe evitar no es el hecho de tratar las acciones de los terroristas, sino que a ellos les guste el modo de ser tratadas" ${ }^{12}$.

Para no favorecer los intereses del terrorismo en el campo de la comunicación, el periódico no debe dedicar al tema terrorista un «espacio sobredimensionado en

8 LAQEUR, W.: Una Historia del Terrorismo, Barcelona, Paidós Ibérica, 2003. p. 162. p. 60 .

- En «Responsabilidad de los medios informativos", Terrorismo y Medios de comunicación social, cit.,

10 Martín TuRrado VIDAL anota cuatro actitudes de la prensa ante el terrorismo: 1) Silencio, 2) Tratamiento Neutral, 3) Tratamiento Limitado y 4) Apología, en "Estudio preliminar", Terrorismo y medios de comunicación social, cit., p. 34-37. Es la clasificación que se sigue en este análisis de Deia.

11 Benegas, J. M..: Op. cit., pp. 159 y 160.

12 . SoRIA, C.: El sindrome de la inseguridad, Barcelona, Drac, 1989, p. 135 
relación con la magnitud o gravedad del hecho". Al terrorismo le interesa estar siempre en los medios de comunicación, para dar a conocer su ideología, sus propuestas y pretensiones. "En el terrorismo (dice el profesor estadounidense Bassiouni) el impacto psicológico es más significativo que el mismo acto de violencia cometido y tal impacto se debe más a la difusión dada por los medios de comunicación que al mismo acto" ${ }^{13}$. De este modo el terrorismo consigue constituirse en un contenido informativo de máximo interés. A veces, la libertad de prensa y el derecho de información se han considerado como justificantes del amplio seguimiento informativo de las actuaciones de los terroristas que en ocasiones hace la prensa, y con el que les da la publicidad que necesitan. Pero el derecho a ser informado (recogido en el artículo 19 de la Declaración Universal de los Derechos Humanos de 1948) implica que los destinatarios de la información tienen también derechos sobre ella, no sólo los informadores. De aquí, se puede deducir fácilmente que, en la información sobre el terrorismo, los destinatarios de la información - la mayor parte de la sociedad agredida - tienen derechos sobre esa información como para poder exigír al informador que se ponga de su lado y no de parte del agresor. En definitiva, es necesario compaginar la libertad del informador que lleva, a su pesar, a prestar un determinado apoyo informativo a los terroristas, y el derecho que la sociedad agredida tiene sobre la información que se le da, pudiendo exigir que esta información favorezca lo menos posible a los terroristas. La cuestión es "no sobredimensionar» y, si es posible, "limitar" la información que pueda generar el terrorismo.

Otro elemento de la información de los actos terroristas a tener en cuenta es lo referente a la publicación de los comunicados que suelen seguir a los atentados. Para los terroristas es tan importante intimidar con sus acciones cruentas como lograr la publicidad de las mismas. Por eso a cada acción terrorista seguirá un comunicado en el que los grupos terroristas, además de adjudicarse la autoría de los hechos, manifiestan la justificación de esa actuación concreta y además las razones y proyectos que la banda tiene para existir y seguir actuando. Por otra parte, con los comunicados, las reivindicaciones, notas informativas, etc., buscan los terroristas mantener centrada sobre ellos la atención de la sociedad. "Por ello publicar un comunicado es ya en sí mismo dedicar un espacio gratuito a la propaganda de la organización y por lo tanto una ayuda a la consecución de sus fines" 14 . Además, la reiteración de informaciones sobre los actos terroristas tiende a encallecer la sensibilidad del público, lo que va a propiciar nuevas acciones terroristas más espectaculares cada vez. Por tanto no resulta aconsejable publicar comunicados de los grupos terroristas cuya difusión alcanza a amplios sectores de la sociedad sobre todo en momentos en que la atención de la gente está captada por el atentado terrorista.

13 Citado por Rivas Troitiño, J. M.: Desinformación y terrorismo. Análisis de las conversaciones entre el Gobierno y ETA en Argel (Enero- Abril 1989) en tres diarios de Madrid, Madrid. Editorial de la Universidad Complutense, 1992.

14 Turrado, M.: Op. cit., p. 31. 
En el tratamiento del terrorismo desde la perspectiva de las víctimas no puede olvidarse la gran importancia de la precisión del lenguaje en la transmisión de cualquier información en general y en lo referente a las noticias generadas por el terrorismo en particular. Esta precisión puede evitar a la prensa convertirse en difusora de lo que quieren comunicar los terroristas. Con todo, es muy frecuente el uso mimético del lenguaje terrorista por parte de los informadores. El profesor de Historia de la Comunicación Carlos Soria dice que urecoger la terminología terrorista en la descripción de los hechos introduce un fuerte componente propagandístico, incluso cuando los términos aparecen entrecomillados». Por su parte, el catedrático Muñoz Alonso afirma que «...quienes simpatizan con el terrorismo y sus causas prefieren darles otros nombres como 'guerrilleros' o 'luchadores' que parecen llevar implícito un elemento de nobleza. Un grupo de terroristas no será una 'banda', sino un 'comando', y su actividad consistirá en 'acciones armadas o militares', no en 'actos criminales o terroristas', la muerte de una persona será una 'ejecución' no un 'asesinato'...”'

La información objetiva y veraz que se sitúa al lado de la víctima y evita favorecer al terrorismo más allá de lo irremediable es el "Tratamiento Limitado», que tiene como bases la veracidad de las informaciones y la tendencia a reducir el espacio dedicado a los actos y comunicados de los terroristas así como la correcta utilización del lenguaje. Si a esto añadimos una posición clara de rechazo del terrorismo en los editoriales del periódico, tendremos las cinco características básicas de dicho tratamiento que nos servirán para estructurar el análisis del diario Deia:

1. Información veraz sobre los hechos exenta de todo carácter sensacionalista.

2. Espacio nunca sobredimensionado en relación con la magnitud o gravedad del hecho. Tendencia a reducir el espacio reservado a hechos, actividades o noticias relacionadas con la organización terrorista.

3. No difusión de ningún elemento propagandístico de la organización terrorista: comunicados, ruedas de prensa, entrevistas personales, reportajes, conmemoraciones necrofílicas de militantes muertos, detenciones, actitudes de presos, campañas dirigidas por la organización terrorista, etc.

4. Utilización de un lenguaje correcto, que no incluya asimilaciones del utilizado por la organización terrorista.

5. Clara línea editorial de condena y rechazo de las acciones terroristas.

15 Muñoz Alonso, A.: El Terrorismo en España, Barcelona, Planeta, 1982, p. 11. 


\section{ANÁLISIS DEL TRATAMIENTO DEL TERRORISMO DE ETA POR EL DIARIO DEIA}

\section{La información veraz en Deia}

No vamos a dudar de la veracidad de la información de los hechos terroristas, en sí mismos, publicados en las páginas de Deia. Pero no es infrecuente que estas noticias estén modeladas por insinuaciones expresas o sugeridas por el modo de transmitir la noticia, o por silencios significativos con los que se transmiten mensajes que ETA quiere hacer llegar a la sociedad ${ }^{16}$. Cuando un medio de comunicación elabora su propia información - Deia no acude a las agencias en la información del País Vasco- va a transmitir a los destinatarios unos parámetros ideológicos determinados con los que procesar la información. La ideología nacionalista de Deia crea la urdimbre que da cuerpo a la información. Y esa urdimbre no es otra que el mensaje reiterado: "El pueblo vasco lucha por las libertades que le han sido arrebatadas "17. Es evidente que esta idea subyace en toda la información del periódico nacionalista, también en la información sobre terrorismo. Por esto, aparte de calificativos diversos que Deia pueda aplicar a los miembros de ETA y aparte de todas las prevenciones que sobre ellos pueda mantener, este periódico transmite la idea de que los terroristas son vascos que, como todos los patriotas vascos, luchan por conseguir las libertades arrebatadas a Euskadi. Ellos son una de las partes que se enfrentan en la «lucha armada"que tiene lugar en Euskadi. La otra parte son las fuerzas de orden público que sinven al Estado que violenta la libertad de los vascos. En este enfrentamiento armado caen de uno y otro bando, vasco y "de fuera". Las víctimas civiles del terrorismo son culpables por no defender los objetivos de los terroristas que son los del pueblo vasco. Veamos cómo Deia transmite a sus lectores estos tres mensajes:

1. La acción terrorista es una "lucha armada» entre dos facciones.

2. Los terroristas son vascos que tienen ideales.

3. Las víctimas son de fuera y son culpables.

\section{La acción terrorista es una lucha armada entre dos facciones}

"Lucha armada" es como le gusta denominar su actuación a la banda terrorista y, como podremos comprobar, es el concepto que transmite generalmente

${ }^{16}$ En este trabajo no es necesario diferenciar las dos organizaciones terroristas que en esta época mantienen las siglas ETA (militar y político militar) pues el objeto del mismo es el análisis de la postura de Deia ante el terrorismo vasco.

17 Esta idea se repite en términos casi iguales tanto en articulos de opinión como en referencias a declaraciones de líderes del PNV, repitiéndose siempre el término «lucha«. Por ejemplo en el artículo de opinión titulado "Un partido en marcha" de Josefa Elósegui, que dice textualmente, refiriéndose a los jóvenes del PNV: «si de verdad luchan prioritariamente por la libertad de Euskadi». José Ramón Scheifler, en «Alternativa a la contraviolencia", dice «...lucha 'no armada', pero lucha", Deia, 22-10-1978. 
Deia, al tratar la actuación de ETA. Si el término "terrorismo" tiene una connotación condenatoria de la parte que realiza el terror y una connotación aprobatoria de la víctima del mismo que, si actúa, se considera que lo hace en defensa propia, en la expresión «lucha armada" se entiende que los sujetos son dos "facciones" que igualmente luchan y están armados. La utilización del término "facción" aplicado a ambos contendientes tiene su razón de ser en que, como veremos, Deia coloca a ambos combatientes fuera de un orden ético, los considera «facciosos». Cuando ha de condenar la violencia etarra, añade que también los otros, las fuerzas del orden público, actúan con violencia, «por eso, una vez más, decimos no a la violencia; a todas las violencias" ${ }^{18}$. Quedarán fuera de un orden ético tanto la violencia física de los etarras y la de las Fuerzas del Orden, como la violencia institucional y moral del Estado español que niega las libertades del pueblo vasco. «Pero, como dice Rafael Aguirre, no se puede dar la impresión de que existen dos violencias, la de ETA y la del Estado, de similar legitimidad, de similar actualidad e importancia» ${ }^{19}$.

Son muy abundantes los textos que pueden traerse aquí para contrastar esta afirmación. Unas veces pertenecen a asiduos colaboradores en artículos de opinión como José Ramón Scheifler quien habla de la violencia de ETA como la "Contraviolencia" y afirma que "mientras Euzkadi no recobre todos sus derechos estará padeciendo violencia, violencia de parte del Estado, del Gobierno y de los partidos en el poder ${ }^{20}$. Otra de tantas manifestaciones en este sentido es el artículo de opinión de Joseba Azcárraga, miembro del Euzkadi Buru Batzar, quien dice que «debe terminar en este maltratado Pueblo Vasco, todo tipo de violencia. No únicamente la violencia desatada por las organizaciones que emplean como método de recuperación de nuestros derechos la lucha armada, sino también esa violencia, tan importante como la anterior, que es la violencia institucional»21.

Todo esto lleva al lector de Deia a un fácil razonamiento: además de la violencia física que ejerce ETA y las Fuerzas del Orden, existe otra violencia institucional que ejerce el Estado español contra el pueblo vasco; ambas violencias son equiparables e igualmente inmorales; quienes las ejercen son dos facciones que están embarcadas en una "lucha armada", es decir, no hay terrorismo, sino "lucha armada" entre dos facciones, entre una y otra "parcialidad de gente en rebelión", como dice el Diccionario de la Real Academia, contra una sociedad que quiere vivir en paz. "Los que queremos una Euzkadi libre y en paz - dice Iñaki Anasagasti, en Deia - al parecer estamos solos; solos ante los armados de ametralladoras de un bando y otro o los de ideas falaces" ${ }^{22}$. En este sentido era fácil escuchar entre la gente sencilla, no politizada de Euskadi: «iLos dos, la Guardia Civil y ETA, son iguales, están locos!».

18 Editorial "No a la violencia; a todas las violencias», Deia, 29-4-1978.

19 AguiRre, R.: El Túnel Vasco, Bilbao, 1994. Libro de gran interés para entender la actuación de la Iglesia en el conflicto vasco.

20 SCHEIFER, J.R.: «Alternativa a la contraviolencia», Deia, 26-10-1978.

21 AzCÁRRAGA, J.: "Libertad y pacificación", Deia, 26-10-1978.

22 AnASAGASTI, 1.: “También seo es violencia", Deia, 9-11-1978. 
La constatación de que Deia transmite esta idea de que el terrorismo de ETA es "lucha armada", queda evidenciada en la no utilización del término "Terrorismo» o "terroristas» para referirse a la actuación o a las acciones y militantes de la organización ETA. En el espacio de tiempo que comprende este estudio, sólo aparece en las informaciones de Deia sobre ETA el término "terrorismo" en dos editoriales con unas peculiaridades propias y en una información en portada con ocasión de la convocatoria del PNV de una manifestación "contra el terrorismo", término que no vuelve a utilizarse aun cuando esta manifestación siguió siendo noticia casi diaria durante diecisiete días hasta celebrarse el 28 de octubre de 1978 , ya con el lema "Por una Euzkadi libre y en paz" ${ }^{23}$ En el editorial titulado Frente a la violencia, diálogo y libertad con ocasión del asesinato del periodista José María Portell, el editorialista habla de la "nueva escalada del terrorismo". No obstante, a continuación hablará de "grupos armados" para referirse a grupos terroristas, y utilizará los términos, "muertes violentas" y "atentado mortal», cuando la lógica del lenguaje coloquial y jurídico nos lleva al término «asesinato» ${ }^{24}$. La segunda ocasión es en el editorial publicado tras el asesinato el día 21 de julio de 1978 en Madrid del general Sánchez Ramos y el teniente coronel Pérez Rodríguez, cuando todavía se pensaba que había sido obra del GRAPO (días después lo reivindicó ETA). En todo el texto no se menciona ETA, pero si el GRAPO y el FRAP y, además de utilizar el término "terrorismo", escribe hasta cinco veces el de "asesinato", cuando siempre que se refiere al terrorismo de ETA lo sustituye principalmente por "muerte violenta»" ${ }^{25}$. El tratamiento de esta noticia nos lleva a la conclusión de que Deia no entiende el "fenómeno ETA» como terrorismo, pues el tratamiento informativo que hace de sus acciones no es el mismo que el de las actuaciones del GRAPO, al que sí reconoce como grupo terrorista. En definitiva, Deia no utiliza prácticamente nunca el término terrorista al referirse a ETA, y esto supone realmente, si no estar con el terrorismo, sí ser condescendiente con el mismo. Como dice Fernando Reinares: «no llamar terrorismo a la violencia que adquiere características distintivas ni por el apropiado epíteto de terroristas a quienes lo han practicado en el pasado o en el presente, cualquiera que fuese su orientación ideológica, se quiera o no, equivale a adoptar una actitud condescendiente, como ciudadanos y como personas, hacia el uso de la muerte como principal argumento político" ${ }^{26}$.

Pero no solamente con la utilización de una terminología inapropiada Deia suaviza la acción terrorista de ETA, sino que también lo hace a través de silencios. De estos silencios podemos hablar, por ejemplo, del que se observa en la información sobre el atentado contra el comandante Imaz de la Policía Armada de Pamplona, el día 26 de noviembre de 1978. En esta ocasión, Deia dice que el comandante recibe varios disparos en la cabeza y en el corazón, pero silencia que estos disparos

23 Deia, 11-10-1978.

24 Editorial «Frente a la violencia, diálogo y libertad", Deia, 1-7-1978.

25 Editorial «El Gran Reto", Deia, 23-7-1978.

26 ReInaRes, F.: Terrorismo y Antiterrorismo, cit., p. 45. 
fueron realizados por la espalda como publican otros periódicos ${ }^{27}$. Indudablemente es un silencio significativo. En la mente de todos está que un disparo por la espalda siempre se asocia a la alevosía y a la vileza criminal, a la vez que impide la posibilidad de conceder al que agrede por la espalda un cierto valor de quien se expone a ser repelido o una cierta justificación de quien actúa en defensa propia. Silencio que atenúa la barbarie de los terroristas, "dos personas armadas", según Deia, lo que nos sugiere una acción militar, tema del que más adelante hablaremos.

\section{Los terroristas son vascos que tienen ideales}

Deia no considera terroristas a los miembros de ETA, sino jóvenes que luchan por unos objetivos que no son otros que los derechos del pueblo vasco. Si Deia huye de considerar la actividad de ETA como terrorismo, esta organización quedará a los ojos de sus lectores despojada del elemento más negativo, que hace reprobable moralmente al terrorismo: «el uso sistemático del crimen y de la destrucción, y de la amenaza de ellos, para aterrorizar a individuos, grupos, comunidades o gobiernos, obligándoles a ceder a las demandas políticas de los terroristas $"{ }^{28}$. En las páginas de Deia se les presenta inmersos en una lucha armada, enfrentándose «militarmente», como gudaris, a las armas del opresor. («La co-

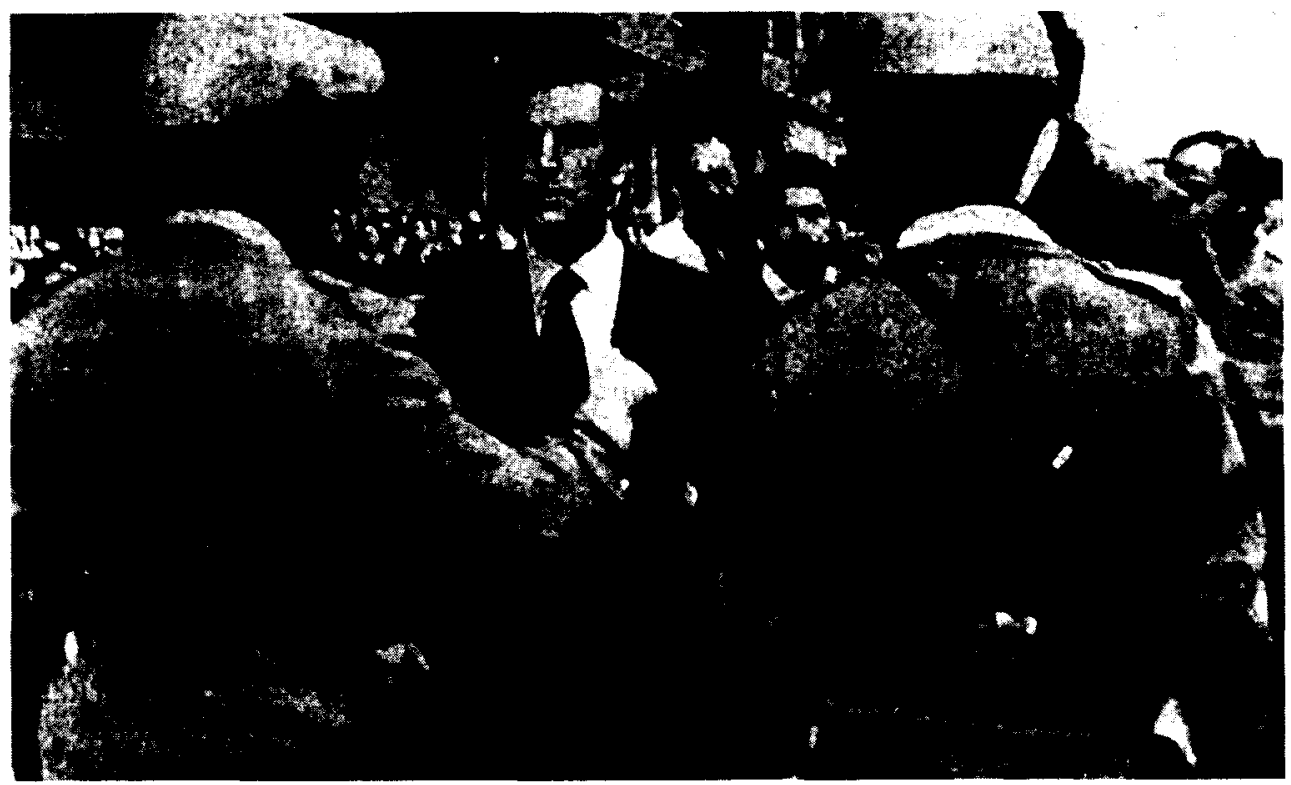

27 El País del mismo día, 27-11-1977, habla de "disparos en la espalda y la cabeza».

${ }_{28}$ WILKINSON, P.: Terrorism and the Liberal State, Londres, Mac Millan,1977, p. 49, en GRANT WARDLAW: Op. cit., p. 56. 
lumna Pertur asaltó el Gobierno Militar de San Sebastián», "Un disparo fortuito desbarató la Operación Zaborra de ETA p-m», son titulares de Deia en primera página, utilizando terminología propia de un ejército regular (los subrayados son míos). La foto que ilustra esta noticia en el lugar más preeminente de la primera página del periódico, en la que un soldado, con el fusil ametrallador en ristre custodia el edificio militar, objeto de la intervención de ETA, nos sugiere un ambiente militar, bélico ${ }^{29}$.

La violencia que llevan a cabo, aparece ante la sociedad no como la violencia calculada cuyas víctimas son elegidas por ser «objetivos vulnerables y en estado de relativa indefensión casi nunca coincidentes con los destinatarios de la violencia ${ }^{30}$, sino como un enfrentamiento con personas armadas que ejercen una violencia anterior. Por tanto, el mensaje que se recibe es que los integrantes de ETA son jóvenes idealistas, exaltados y confundidos, pero jóvenes del Pueblo Vasco ("respetados profundamente" como decía Arzalluz ${ }^{31}$ ) que están en una lucha "loca» contra la fuerzas armadas de un estado que impide el disfrute de las libertades al pueblo vasco. Aparecen en las páginas de Deia como soldados patriotas que luchan, aunque "exageradamente", por unos ideales. "Son gente del pueblo que lucha, sufre y muere por el pueblo".

Son gente del pueblo. Al leer las páginas de Deia, cualquier lector sin prevenciones entiende que los miembros de ETA son jóvenes que tienen su entorno familiar, trabajo o estudios en el País Vasco, como los demás miembros de la sociedad. La gente del pueblo los conoce y los defiende cuando la policía los detiene, cuando están en la cárcel, y lloran por ellos cuando mueren. Incluso son un colectivo con más conciencia nacional, porque exponen hasta su vida por los intereses del pueblo. Desde otro punto de vista esta mayor conciencia nacional también se puede deducir del artículo de Luis A. Aranberri, en el que este autor constata que «el porcentaje de vascoparlantes entre los activistas de ETA sea dos o tres veces superior al porcentaje de vascoparlantes de todo Euskadi", mientras que "el PSOE no tiene ni la mínima incidencia en el movimiento de ikastolas. La relación entre idioma y conciencia nacional es indiscutible...."32.

Son gente que lucha por su pueblo. El terrorismo es un medio para conseguir unos objetivos. En los actos terroristas nunca hay gratuidad o irracionalidad y se pretenderá siempre justificarlos con los objetivos perseguidos ${ }^{33}$. Los objetivos de ETA, por los que actúa siguiendo la estrategia del terror, son los que pueden defender muchos nacionalistas vascos. En continuas ocasiones, en artículos de opinión y editoriales aparecen en Deia afirmaciones de este tipo: las libertades del pueblo vasco, que también defiende ETA, se pueden defender de otra forma. En la

29 Deia, 20-6-1978.

30 EZZAT A. FATTAH: "Some reflections on the victimology of terrorism", Terrorism, vol. 3 (1979), pp. 81-118.

31 Deia, 18-1-1978.

32 Aranberri, L. A.: “La Agonía Vasca», Deia, 12-5-1978.

33 WardLaw, G.: Op. cit., pp. 57-58. 
práctica totalidad de los numerosos comunicados de ETA se explicitan algunos puntos de su programa político que coincide, en lo fundamental, con la ideología nacionalista de Deia. Es, por tanto, un programa justo por el que luchan todos los nacionalistas.

Son gente que sufre por su pueblo. No es necesario ser demasiado perspicaz para deducir que en las páginas de Deia se percibe una cierta piedad y compasión por los terroristas que sufren no sólo las penurias y privaciones que impone su opción de clandestinidad y persecución por la justicia, sino también sufren por la abusiva actuación de las fuerzas de seguridad. Si leemos algunos titulares de Deia sobre detenciones, registros, interrogatorios, etc, aparece con total evidencia que Deia transmite una simpatía cómplice con los terroristas que se han puesto fuera de la ley y una persistente duda sobre la actuación de las fuerzas de seguridad.

Son gente que muere por su pueblo. Son jóvenes que sufren más que el común de los patriotas por causa de las libertades de Euskadi, hasta morir por ellas. Para comprobar cómo Deia contribuye a la creación del arquetipo del militante de ETA como joven que sufre y muere por su pueblo, podemos acudir, de nuevo, al titular del día 18 de enero de 1978: «Arzalluz: Respetamos profundamente a los vascos que mueren por su pueblo" (Aquí es conveniente recordar que el 11 de enero han muerto dos etarras y un comisario de policía en un enfrentamiento en Pamplona). No es necesario hacer ningún discurso argumental para afirmar con rotundidad que, con esta declaración de uno de los principales dirigentes del PNV, partido con el que coincide la línea de pensamiento de Deia, este periódico, si no crea, contribuye a mantener en la sociedad vasca la idea de que los activistas de ETA no son terroristas sino "jóvenes vascos que mueren por su pueblo", que dan su vida por Euskadi.

\section{Las víctimas son de fuera y son culpables}

Policías y guardias civiles. El colectivo de la Policía y Guardia Civil es el más castigado por ETA a lo largo de su actividad terrorista. En 1978, año en el que se centra este estudio, casi la mitad de las víctimas son policias y guardias civiles (34 de los 69 asesinados) En los planes de ETA está el atentado indiscriminado contra policias y guardias civiles, la mayoría de las veces sin cualificación y sin significación política, que, como ETA misma reconoce en Carta abierta a los miembros del aparato policíaco de Euskad ${ }^{34}$, están en estos Cuerpos por razones de trabajo, casi nunca por ideología. La causa de esta elección de víctimas tiene dos vertientes: una simbólica y otra estratégica y, como telón de fondo, la intención didáctica dirigida al pueblo vasco. Para ETA representan y son el símbolo y el elemento más visible del Estado represor que tiene tomada a Euskadi. Por otra parte, en su estrategia está crear terror en este colectivo, crear desánimo y fomentar el odio a todo lo vasco en sus miembros para que "cumplan a la perfección" su papel de

${ }^{34}$ Panfleto de ETA de 1965, publicado en Hórdago, p. 159, t. 5. 
elemento represor en la estrategia "acción-represión „35. De este modo, al ejercer una represión más contundente, se granjearán el odio del pueblo, «por la sencilla razón de que os conocemos", dice la carta ya aludida. Con esto ETA pretende enseñar al pueblo que realmente existe una fuerza de ocupación en el País Vasco, que utiliza una represión brutal, continuación del franquismo, que estos hombres concretos odian al pueblo vasco, son enemigos del mismo y por tanto hay que acabar con ellos. Sólo con la violencia - dicen - van a lograr que España negocie y a conseguir la independencia, como único medio para evitar la indignidad y la agonía del Pueblo Vasco, de su cultura, su lengua y su derecho al autogobierno ${ }^{36}$. En resumen, con estos atentados ETA quiere comunicar al pueblo que:

- Los guardias civiles y policías son personas que traicionan y odian todo lo vasco.

- Son una fuerza represora, extraña al pueblo vasco, y ellos mismos son de fuera.

- Sus métodos son franquistas y antidemocráticos.

- Tienen más armas, por lo que la acción terrorista es justificada.

Para la transmisión de estas ideas, ETA va a acudir en primer lugar al atentado, proyectado desde una estrategia bien definida, $y$ en segundo lugar se va a servir de la capacidad de difusión de los medios informativos. Estos medios pueden tomar diferentes posturas ante la misión que ETA quiere que cumplan. Unas veces puede ser de total sumisión a los dictados de ETA -como Egin y Punto y Hora ${ }^{37}$-; otras, adoptando una postura de libertad e independencia frente a la organización, pero dejando traslucir una mayor o menor simpatía por los terroristas. Deia, adoptando la segunda postura, no está al servicio de ETA, pero sive a los intereses de ETA. Unas veces este servicio no deja de ser el tributo lógico e inevitable al terrorismo - hacer públicas sus acciones como quiere y necesita el terrorismo- que la libertad de prensa y el derecho de información piden a todo medio informativo en una sociedad democrática ${ }^{38}$. Otras veces este servicio a la propaganda y difusión de lo que ETA quiere transmitir a los ciudadanos, viene dado, por una parte, por la publicación de comunicados de ETA, por otra parte, a través de la información de actuaciones policiales, teñida de opiniones y suposiciones que insinúan un juicio negativo de la policía y una visión cercana a las tesis de ETA. Por ejemplo cuando Deia informa de actuaciones policiales llevadas a cabo en Rentería a primeros de enero de 1978, se dice en la entradilla de la noticia: «la operación policial fue efectuada al estilo de las 'redadas' que se hicieron en Euskadi durante los estados de excepción que tuvieron lugar en los tiempos del franquismo". El titular de esta información dice: «Policias armados con metralletas detuvieron a 15 personas». EI

${ }^{35}$ En «Bases teóricas de la guerra revolucionaria», ponencia aprobada en la VI Asamblea de ETA, 1965, Comentarios, Hórdago, t. 3.

${ }^{36}$ En la revista interna de ETA, Zutik, $n .{ }^{\circ} 26,1965$

${ }^{37}$ Roson, J.J.: «El caso de España», en Terrorismo y medios de comunicación social, cit., pp. 147149.

38 AZNAR, H.: Ética de la comunicación y nuevos retos sociales, cit., pp. 189 y ss. 
antetítulo, subrayado: «Redada de madrugada en Renteria» ${ }^{39}$. A nadie se le escapa que la utilización del término «metralletas» en el titular da un carácter más militar que policial a la operación llevada a cabo por la policía, favoreciendo el mensaje que ETA quiere transmitir: que los cuerpos de seguridad son un ejército ocupante. Asimismo, el término "redada» -que no está utilizado con ningún rigor- sugiere una acción indiscriminada, represora y sin control de lo que fue, en realidad, un registro y detención con orden judicial ${ }^{40}$. La referencia a los estados de excepción de los tiempos del franquismo vierte en la conciencia del lector el mensaje de que la policía que persigue la delincuencia de ETA es la fuerza represora de la dictadura que todavía sigue "ocupando" Euskadi. Otras veces el redactor muestra una actitud de menosprecio de la actuación policial, introduciendo en la información opiniones y sugerencias que mueven al rechazo de dicha actuación, como la información que aparece en primera página el día 8 de enero de 1978 que dice en el antetítulo: “Como la Operación Puño en Francia, pero a la española" (el subrayado es mío), para informar de detenciones a sospechosos de estar relacionados con la organización ETA.

Podemos ver también en el material gráfico publicado por Deia, esta tendencia del periódico a trasmitir al lector que los cuerpos de seguridad, cuando menos, no favorecen la paz en el País Vasco. La fotografía en la prensa es un lenguaje, nunca inocente, que presenta no sólo una imagen que completa la información escrita sino también, muchas veces, es el vehículo de un mensaje que sobre dicha información el periodista pretende transmitir. Deia también utiliza la imagen para transmitir información y opinión. Vamos a analizar dos fotografías publicadas por Deia que nos pueden dar más detalles sobre la línea informativa de este periódico en relación con ETA. En el siempre importante seguimiento que hace de las manifestaciones del nacionalismo radical, en las que, como el mismo diario informa, se lanzan gritos favorables a ETA y contrarios a la Policía y la Guardia Civil ("ETA herria zurekin" (ETA, el pueblo está contigo); "ETA, jarraitu borroka harmatua" (ETA, prosigue con la lucha armada); "Queremos vivir sin Guardia Civil», etc.) es habitual que aparezcan fotografías con las que se ilustra la información. Fotografías que lanzan mensajes muy significativos. Así, en la foto que publica Deia el 10 de enero de 1978 de una manifestación celebrada en San Sebastián, en un primer plano aparece un perro que avanza en solitario caminando por un gran espacio de calzada vacio por delante de la pancarta que abre la manifestación. En la pancarta una sola palabra: «Independenztia». En el antetítulo se dice: "La manifestación, sin que hiciera acto de presencia la fuerza pública, en perfecto orden y sin el menor incidente" No es necesario acudir a las teorías sobre del valor de la imagen en la prensa ${ }^{41}$ para afirmar que un ciudadano vasco, que sabe que los po-

39 Deia, 4-1-91978, p. 3.

40 El mismo dia El País publica esta noticia con el título: «Inmensa actividad policial en el País Vasco" en la que se afirma que actuó “...la policía provista de órdenes de registro dictadas por el Juzgado número 1 de Madrid que instruye las diligencias".

41 Sobre este tema puede consultarse Huici Módenes, A.: Estrategias De la persuasión. Mito y propaganda política, Sevilla, Afar, 1996; Cebrián, M... La información audiovisual. Un servicio a la sociedad, 


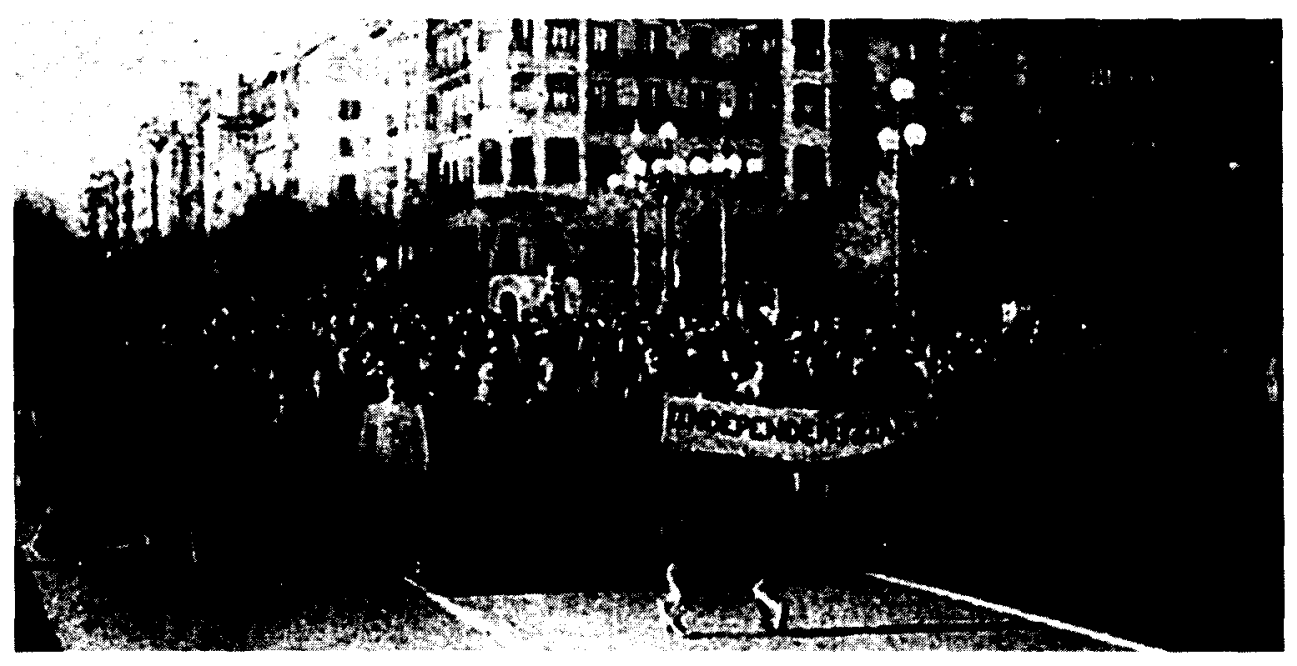

licías son insultados en determinados círculos populares con el término "Txakurra» $(\text { perro })^{42}$, al ver la fotografía y leer los titulares, enseguida va a relacionar los tres conceptos que sugiere la fotografía: Independentzia (escrito de la pancarta); $\sin$ incidentes (la calzada vacía que sugiere el orden en que transcurre la manifestación) y sin policias (el perro que vagabundea sin crear inquietud, lo contrario que los policias que no están).El mensaje captado es sin duda: Independentzia que piden todos pacíficamente porque no está la fuerza pública real, sólo su imagen: el perro.

Otro ejemplo de la utilización que Deia hace de la imagen para transmitirnos juicios de valor sobre las Fuerzas de Orden Público, es la fotografía que se publica en la primera página del 29 de octubre de 1978, con motivo de la manifestación convocada por el PNV con el lema «Por una Euskadi libre y en paz». En la fotografía, el espacio está casi lleno con dos policías y sus cascos que la cámara ha tomado por la espalda, de la cintura para arriba. Entre ambos, en un segundo plano, en el centro de la fotografía, la imagen frontal, digna, sublimada, de Carlos Garaicoechea, que avanza seguro y dialogante, pero que es parado por la muralla policial. Si la imagen "conlleva juicios de valor disimulados, que son interiorizados de modo subliminal, sin ser percibidos, al menos conscientemente, por el lector de los diarios" ${ }^{43}$, en este caso son dos los juicios de valor que va a interiorizar el lector: $1 . \circ$, la fuerza pública es una barrera, un grave obstáculo para que avance Euskadi; 2. ${ }^{\circ}$, ni el presidente del PNV, que es un hombre dialogante, firme y seguro, conseguirá que Euskadi avance. Este mensaje está reforzado por el pie de foto que dice: «En un principio las FOP - Garaikoechea dialoga con ellas - no admiten un

Madrid, Forja, 1983, y DeBray, R.: Vida y muerte de la imagen. Historia de la mirada de Occidente, Barcelona, Paidos Comunicación, 1994 (en origen, Editorial Gallimart, 1992).

${ }^{42}$ El término "txakurra" lo utilizaba ETA en publicaciones internas ya desde los años sesenta. Por ejemplo en Zutik Berriak de marzo de 1968. Documentos. Hórdago. T 7, p. 474.

${ }^{43}$ Rekalde, A.: Prensa y propaganda. EI Nacionalismo vasco en EI País, Tesis doctoral, Lejona, Universidad del País Vasco, 2000, p. 236. 
cambio de itinerario". Por tanto, la idea que se transmite a los lectores es que las fuerzas de orden público son una verdadera muralla que detiene la marcha del Pueblo Vasco. Y los lectores, captada esta idea, van a ser terreno propicio para que ETA pueda sembrar su argumentación: la violencia terrorista contra guardias civiles y policías está justificada porque paran nuestro avance como pueblo y porque la actitud dialogante de algunos nacionalistas no sirve para impedirlo.

Otras víctimas. Si bien el principal objetivo de los atentados de ETA en la Transición son los cuerpos de seguridad del Estado y los miembros de Ejército en un intento de desestabilizar la democracia, también otros sectores de la población civil fueron blanco de sus atentados. Si los atentados contra miembros de los aparatos del Estado, los justificaba ETA porque formaban parte de una fuerza de ocupación contra la que ETA mantiene una guerra de liberación, los atentados contra civiles los justificará en general porque eran «enemigos de Euskadi»; unas veces, porque eran "chivatos" o "colaboradores del enemigo", otras, porque eran "traidores" que en el pasado hicieron sufrir a los vascos.

Cuando el terrorismo elige el blanco de sus atentados busca crear angustia y ansiedad en la población ${ }^{44}$. Esta ansiedad surge de la dificultad de dar respuesta al por qué de la elección de las víctimas de los atentados. Es necesario encontrar una razón para apaciguar la angustia que produce el no saber si cualquier ciudadano puede estar en el punto de mira de los terroristas. La primera respuesta que, como autodefensa primaria, elabora la gente para acallar esa zozobra es el «algo habrán hecho" ${ }^{45}$, o la simple aceptación, sin mayores razonamientos, de la explicación que, inmediatamente después del atentado, dará ETA en sus habituales comunicados. "Muchos consideran - dice Mario Onaindía - que sería espeluznante que todos los asesinatos y crímenes cometidos por la organización terrorista no tuvieran una causa profunda, cuya comprensión se nos escapa [...] Por eso se aferran a la convicción de que tiene que ser verdad lo que dice ETA y aquellos nacionalistas que justifican sus acciones, porque si no, sería terrible» ${ }^{46}$. De esta preocupación participa Deia cuando informa de estos atentados. Si analizamos la información que Deia hace de los atentados civiles, observaremos la preocupación insistente del periódico por responder cuanto antes a las mismas cuestiones: ¿Había sido amenazada la víctima? ¿Su ideología era de extrema derecha? ¿Qué actividades políticas había realizado en el pasado?

Parece que en la respuesta de estas tres cuestiones está la explicación de por qué ETA ha elegido a la víctima de su acción terrorista. Las respuestas que dé Deia serán contrastadas con el comunicado que publique luego ETA y que recogerá en sus páginas el periódico. Por supuesto, el veredicto de ETA no será casi nunca discutido. Si lo primero que se dice del atentado es que la víctima estaba

44 Reinares, F.: Op. cit., p. 36.

45 Entrevista no publicada que realicé a Imanol Murua, exdiputado General de Guipúzcoa el 22 de febrero del 2004, en Zarauz (Guipúzcoa).

46 Onaindia, M.: Guía para orientarse en el laberinto vasco, Madrid, Temas de Hoy, 2003, p. 211. 
amenazada, se dará en el lector una predisposición a aceptar que, posiblemente, era culpable y, por tanto, se podría dar alguna justificación al atentado. Resulta inquietante para un pensamiento democrático que Deia trate de aclarar con tanta premura este asunto. Muchas veces la información del atentado se inicia, preferentemente en el título o el antetítulo de la noticia, con esta información: la víctima había sido amenazada. Es una información propia recabada con urgencia $-y$ por la premura, con dudosa confrontación de fuentes - de vecinos, personas que conocian a la víctima, etc. Otro elemento que Deia considera importante para llegar cuanto antes a la causa del atentado es comprobar la ideología de la víctima, si es "muy de derechas" o de "extrema derecha". Así, dice el titular que informa sobre el atentado contra el juez de paz de Lemona (Vizcaya) «J. J. Jáuregui, muy de derechas". En la información del atentado en el que un joven de 25 años y su novia son disparados a bocajarro cuando estaban sentados en un bar de Guernica, se resalta en el texto: “Estaba considerado guerrillero de Cristo Rey" ${ }^{47}$. Deia parece que relaciona la ideología de extrema derecha con los enemigos de los símbolos y la cultura del pueblo vasco cuando dice del ex teniente de alcalde de Castillo, Elejabeitia, ("Muerto a tiros") que «...era de ideologia de extrema derecha y su nombre había aparecido en los periódicos como autor de unos disparos de escopeta contra una ikurriña y contra varios jóvenes de Castillo que cantaban en euskera» ${ }^{48}$. Por otra parte ETA lo está diciendo continuamente: la ideología de extrema derecha es propia de los enemigos del Pueblo Vasco, por eso en muchos de sus comunicados avisa y amenaza: «Es la última y definitiva advertencia a los ultraderechistas»49. De tal manera está en la opinión pública que tener la ideología de derechas puede ser motivo de culpabilidad, que los familiares de las víctimas se apresuran a aclarar que la víctima, aunque "tenía ideología de derechas, no era un hombre político, no pertenecía a ningún partido" ${ }^{50}$. Otras veces, cuando la victima sobrevive se justifica ante el pueblo: «Nunca fui amenazado, ni tuve nada que ver con la Falange [...] procedo de los Tradicionalistas y ahora estoy lejos de cualquier partido de derechas $"{ }^{51}$.

Finalmente, Deia informa sobre el pasado de las víctimas, con lo que sus lectores podrán tener razones para suponer que, si han sido asesinadas por ETA, puede ser por ese pasado comprometido por el que ETA les recuerda: "No olvidamos". En conclusión: el lector de Deia al acercarse a la información sobre los atentados de ETA va a tranquilizarse pronto porque entiende que las víctimas de las atrocidades cometidas por ETA son, de algún modo, culpables. No le va a resultar dificil comprender que, si han sido amenazados, o tenían una ideología ultraderechista o tienen un pasado político contrario al Pueblo Vasco, ETA haya decretado su muerte. Porque - como arriba decia Onaindia - piensan que utiene que ser verdad lo que dice ETA [...] porque si no, sería terrible»

47 Deia, 4-11-1978, p. 6.

48 Deia, 17-3-1978, p. 1.a.

49 Deia, 8-6-1978, p. 3.

50 Deia, 28-11-1978, p. 9.

51 Deia, 15-4-1978, p. 1.a. 


\section{Espacio del periódico Deia dedicado a ETA}

El tratamiento del terrorismo en la prensa que denominamos «limitado" y cuyas características seguimos como parámetro en este análisis del periódico Deia, supone que, para no favorecer los intereses de los terroristas, el espacio del periódico dedicado a las noticias generadas por el terrorismo no sea sobredimensionando sino más bien limitado si fuera posible. También requiere este tratamiento medir con rigor los espacios destacados que ocupen dichas noticias. Pues bien, al examinar los números de Deia pertenecientes al periodo de tiempo que ocupa este trabajo, la primera conclusión que se recoge es el importante número de días en los que el diario dedica un espacio a la información sobre ETA (257 ejemplares de los 324 examinados). También observamos la preeminencia que se da a la información que ETA genera, si consideramos el número de días que esta información aparece en la primera página (152). Si hacemos una comparación de estos datos con los espacios dedicados a los acontecimientos políticos que durante todo este periodo afectan continuamente a Euskadi, generando información persistente (la elaboración de la Constitución, con la pugna sobre el reconocimiento de los derechos históricos vascos o la preautonomía recién estrenada, con la polémica sobre la integración de Navarra y la creación del Consejo General Vasco), detectamos que no superan, en modo alguno, los espacios dedicados a ETA. Incluso hay meses en los que alguno de estos temas tiene una mayor incidencia en la prensa por alcanzar el punto álgido de la polémica o el desenlace de la «trama» y que, por el contrario, son meses en los que ETA ha tenido una menor actividad terrorista, $y$ sin embargo el espacio dedicado a estos temas no es mucho mayor que el que se dedica a ETA. Sirva como muestra el mes de septiembre de 1978. En este mes se decide en el Senado la inclusión en la Constitución del reconocimiento de los derechos históricos vascos. La discusión pasa por muy diversos momentos en la Comisión Constitucional del Senado: unas veces el texto propuesto por los nacionalistas vascos sale adelante con los votos del PSOE (EI Senado reconoce los derechos históricos forales, publica Deia en $1 .^{\text {a }}$ página el día 18), otras el proyecto es rechazado por UCD ( No hay acuerdo UCD-PNV, 1. a página del día 12). Se trata, como vemos, de un tema destacado que genera información diaria y ocupa un espacio en la portada de 12 de los 26 diarios publicados en el mes. Por otra parte, ETA, que durante este mes ha tenido una actividad escasa, en comparación con otros meses de este cruento año (dos atentados mortales), ha ocupado espacio en 7 portadas.

En un leve intento de estudio comparativo de la dedicación de espacio al tema de ETA, es conveniente considerar algunos datos sobre este asunto de un periódico nacional como El País y contrastarlo con Deia. Este diario dedica en el mes de octubre titulares relacionados con ETA en la portada del diario, 7 días. Deia, por su parte, dedica espacio a ETA en 16 portadas de los diarios del mismo mes. En los 24 números publicados en el mes de noviembre, El País concede espacio en la 1. a página a la información relacionada directamente con ETA, en 14 de ellos. Deia lo hace en 22 (hay que tener en cuenta que este es el mes más sangriento, con diez días con 
atentados mortales de ETA). A la vista de estos datos podemos concluir que en Deia la información sobre ETA es continua, casi permanente en todos los números del periódico. Es evidente, como se ha documentado antes, que esto es lo que quiere el terrorismo en general y ETA en particular: estar permanentemente en contacto con el pueblo a través de los medios de comunicación, lo que le da una enorme capacidad de transmitir sus propuestas sobre lo que es y ha de ser Euskadi, pudiendo influir en la creación de una conciencia nacionalista radical en gran parte de la población vasca y justificando su sangrienta actuación:

"El efecto en el receptor de la información es el de considerar de hecho a ETA como poder fáctico. La organización adquiere un protagonismo en la opinión pública que está lejos de merecer. La propaganda es por lo tanto algo sagrado e intocable» (Martín Turrado: «Terrorismo y medios de Comunicación», p.32).

\section{Los comunicados de ETA en Deia}

El tercero de los presupuestos del "tratamiento limitado" del terrorismo en la prensa recomienda no publicar elementos propagandísticos de la organización terrorista: comunicados, detenciones, actitudes de presos, campañas dirigidas por la organización... En Deia, todo lo referido a ETA es materia de publicación en sus páginas. No sólo se publican sus actuaciones violentas de mayor o menor importancia, con derramamiento de sangre o sin él, sino también todos los avatares y situaciones que acontecen a sus miembros: si son detenidos y cómo han sido detenidos; si son interrogados en comisaría y cómo han sido estos interrogatorios; cómo se han desarrollado sus funerales y las consiguientes manifestaciones de sus seguidores; los problemas de los presos en las cárceles y las manifestaciones de quienes pretenden que salgan de ellas; los problemas internos de la Organización como todo lo referente al cruce de acusaciones entre diversos sectores en torno a la muerte de Pertur, y, sobre todo, los comunicados en los que nos vamos a detener en nuestro análisis.

Los comunicados de los terroristas son un elemento decisivo de su acción violenta. Publicarlos es dar una oportunidad inmejorable a la vertiente propagandística del terrorismo. Los comunicados son un medio que necesita el terrorismo para comunicarse con la sociedad, para hacer declaraciones programáticas, exponer su ideología y objetivos, justificar sus actuaciones, mandar mensajes a sus oponentes, hacer llamamientos, denuncias de situaciones, etc... Deia no evita la publicación de ninguno de estos comunicados. Unas veces se publica el comunicado íntegramente; otras, la mayoría, lo que se publica es una reseña o paráfrasis del comunicado. Pero como dice en su tesis el profesor Fernando Ripoll, «parafrasear las reivindicaciones de los comunicados terroristas no anula ni los efectos propagandísticos de la acción ni el valor objetivo de sus reivindicaciones entre los que una buena parte serán asumidas por la población". Por otra parte en las reseñas siempre se acude a frases textuales que son consideradas por el periódico como las más significativas del contenido del comunicado. Esto establece una cierta 
complicidad entre el medio de comunicación que lo publica y la parte del comunicado recogido. De la atención que Deia dedica a los comunicados de ETA, dan buena muestra los datos siguientes: treinta y tres comunicados de ETA ocupan parte de la primera página (a veces con grandes titulares) y treinta y cinco aparecen en el interior del periódico.

Deia, por tanto, resulta ser una tribuna de difusión de la ideología, estrategia, mensajes y opiniones que ETA quiere transmitir a la sociedad en su conjunto o a un determinado sector de la misma al que se dirige para amenazarle, responderle - acusarle. Si leemos los comunicados que ETA publica en las páginas de Deia podremos conocer la ideología, planes y estrategia de ETA; los mensajes amenazantes a distintos colectivos de la sociedad (a la prensa, a los colaboradores con el enemigo, a los que han hecho sufrir en el pasado a ciudadanos vascos, a militantes de grupos políticos enemigos del pueblo vasco); las opiniones y consignas de ETA; las aclaraciones que precisa hacer la organización sobre atentados más controvertidos y las comunicaciones al Gobierno y a partidos políticos. Después de estas constataciones no es posible dudar de que la publicación de los comunicados de los terroristas es un inestimable apoyo a sus fines y objetivos. Asimismo, esta publicación de los comunicados es, como dice Turrado, un magnífico «espacio gratuito para la propaganda" de la causa terrorista. De esta manera, Deia al publicarlos está prestando también un apoyo económico a ETA, sin pretenderlo.

\section{Uso mimético del lenguaje de ETA}

Son muchos los autores que, desde diferentes campos del saber, han reflexionado sobre las posibilidades del lenguaje para manipular la información y han avisado sobre la posibilidad de ganar batallas con un medio de "temible ambigüedad" como es el lenguaje. En este sentido, el reconocido lingüista Teun van Dijk dice que "la estructura retórica y ciertas superestructuras pueden dar pie a una manipulación de los sentimientos, las opiniones y las posturas de lectores y oyentes" ${ }^{52}$.

Los grupos terroristas no han pasado por alto la utilización del lenguaje como arma para difundir sus ideas y conseguir sus propósitos. Han conseguido elaborar un vocabulario adecuado a su deseo de intentar dignificar su actuación. Los terroristas han conseguido que este vocabulario haya sido adoptado consciente o inconscientemente por la prensa en general. Este hecho supone una primera victoria para el terrorismo. Pero lo más importante de esta utilización del lenguaje que elaboran los terroristas no es la utilización en sí misma, sino la previa interiorización del periodista de esa manipulación del lenguaje. Miguel Ángel Aguilar decía a este respecto: «El problema radica en que nuestro propio sistema lingüistico esté manipulado antes de que pronunciemos palabra: en que las expresiones que a un determinado grupo no le convienen las pensemos entre algodones. No sólo que las

52. Citado por Rivas Troitiño: Op. cit., p. 63. 
pronunciemos con suavidad y temor, sino que incluso aniden en nuestro subconsciente previamente edulcoradas. De este modo los verdaderos conceptos parecen darnos miedo, y la realidad queda entonces disfrazada y escondida ${ }^{53}$.

Deia, como hemos analizado ya en páginas anteriores, utiliza muchas veces en su información sobre ETA los mismos términos que aparecen en los comunicados de esta organización terrorista. Es evidente que dichos términos son los elegidos por ETA para describir y justificar sus actos violentos, pero no los más adecuados si nos ponemos del lado de las víctimas y de la sociedad que es también agredida por el terrorismo. Por otra parte, Deia evita términos en lo que respecta a ETA, como "terrorismo" y "asesinato" cuya no utilización evidencia una determinada postura ante el fenómeno ETA. Y finalmente, en ocasiones, para describir acciones o situaciones de miembros tanto de ETA como de la Policia, acude a vocablos que utiliza con dudosa propiedad, con lo cual puede crearse una cierta confusión entre los lectores.

Podemos afirmar que en Deia la utilización del lenguaje en lo referente a ETA está muy influida por la terminologia que la organización terrorista se da a sí misma. Unas veces puede ser por puro mimetismo y ufrivolidad general de la prensa", como dice Aróstegui, pero también es claro que otras veces el uso de este lenguaje, al parecer impropio para informar sobre el terrorismo, tiene su origen en convicciones ideológicas de los periodistas de Deia en torno a la definición de la violencia de ETA que no es considerada nunca como terrorismo.

\section{Línea editorial de Deia}

La ideología nacionalista y democrática en Deia. Esta ideología nacionalista moderada está presente en los editoriales y artículos de opinión de este periódico. La mayor parte de los artículos de opinión están firmados por nombres de clara ideologia nacionalista, cercanos al PNV, unas veces sin militancia declarada en el partido y otras no sólo con militancia sino también con cargos notables en el partido o en las instituciones políticas. Por esta razón analizaremos no sólo sus editoriales sino también los artículos de opinión publicados en sus páginas. Para Deia su principal objetivo es la defensa de la identidad del pueblo vasco "en su lengua, cultura e instituciones" ${ }^{54}$. Una identidad que ha de "recuperar" porque "sus derechos le fueron arrebatados". "Tenemos derecho a exigir que se nos restituya lo que se nos ha quitado" ${ }^{55}$. Las ideas del nacionalismo sabiniano están en el fondo de estas expresiones y son expuestas en artículos que recuerdan los pactos con la Corona del pueblo vasco, hablando de la "Constitución vasca» respetada hasta 1839 . Éste, dicen, es el problema vasco que en Madrid no entienden "porque en Madrid siempre

\footnotetext{
${ }_{53}$ GriJelmo, A.: El estilo del periodista, Madrid, Taurus, 1997, p. 527.

54 Editorial, Deia, 8-6-1978.

55 Editorial, Deia, 15-7-1978.
} 
se habla de 'dar' o 'no dar', cuando el término correcto es 'devolver' ya que los vascos se dieron ellos mismos su propia Constitución y este hecho ha sido aceptado y ratificado por la Corona hasta $1839 . . .{ }^{56}$. A veces la defensa del nacionalismo se hace desde planos más filosóficos, pero siempre desde la concepción del nacionalismo como una identidad histórica, anterior a toda realidad social. Así en el artículo "Elogio del Nacionalismo" se afirma que "los nacionalismos son exigencias del ser, anteriores a las diferencias socioeconómicas realizadas por el hombre»57.

La frase "No nos entienden», que es muy frecuente tanto en titulares de artículos y declaraciones de políticos como en los textos de editoriales y artículos de opinión, expresa no sólo la decepción de los nacionalistas, sino también un sentimiento de suspicacia, prevención y rechazo hacia el Gobierno y los partidos políticos que no aceptan sus reivindicaciones nacionalistas. De este modo, son frecuentes las críticas al gobierno y a la UCD con las que se les acusa, a veces con dureza, de no querer solucionar el problema vasco y de desprestigiar a Euskadi como se dice en el editorial titulado "Rueda de prensa lamentable" del 15 de julio: «Lamentable porque, una vez más, el Gobierno ha intoxicado a la opinión pública del Estado español: ha distorsionado la verdad de los últimos acontecimientos, ha ocultado las raíces del problema vasco y, en definitiva, ha deformado la imagen de Euskadi». EI PSOE, al que el PNV y también Deia han considerado compañero de viaje en temas importantes como la defensa de la incorporación de Navarra al Consejo General Vasco y la creación de dicho Consejo, no es tampoco de fiar. Cuando no sigue la línea marcada por el PNV, surgen las críticas acusándole de "sucursalista»; de "ponerse las lentes de UCD"; de ser "como el caballo de Troya del centralismo [...] que pretende introducirse en el Pais Vasco con una misión muy concreta..." "58; de "vender las libertades de los ciudadanos del País Vasco a cambio de las ventajas partidistas obtenidas en Madrid, mediante la cortina de humo de su ataque al PNV ${ }^{59}$.

En el editorial titulado «El gran Reto» (22 de julio de 1978) podemos constatar el sentir democrático de Deia que alza su voz en defensa de la democracia naciente en España y clama contra los que buscan acabar con ella, provocando un levantamiento militar. Al mismo tiempo avisa con prudencia a los militares de que la vía golpista no soluciona nada y está abocada al fracaso. Este editorial se origina a raíz del asesinato de dos militares en Madrid (atribuidos en un primer momento al GRAPO, luego y definitivamente a ETA) que provocó un gran desasosiego en el país por temor a la reacción del Ejército. Deia denuncia a esos focos de franquismo inmovilista insinuando la posibilidad de que estén detrás de estos atentados provocadores del GRAPO y pide a todos el respaldo a la democracia. Este editorial

56 GamboA, J. M.a: «La paz en Euskadi pasa por la devolución de las libertades vascas el pacto con la Corona", Deia 20-5-1978.

57 SHEIFLER, J.R.: “Elogio del nacionalismo», Deia, 26-9-1978.

58 Ruiz Cebeiro, E.: «El Caballo de Troya Psoeista", Deia, 13-10-1978

59 BIZKAITARRAK: "No al juego del PSOE con las libertades vascas", Deia, 30-9-1978. 
es uno de los raros momentos en que Deia expresa las inquietudes democráticas al unísono con todos los ciudadanos demócratas españoles, trascendiendo el ámbito del Pais Vasco. Es también uno de los pocos editoriales en que Deia utiliza el «nosotros" para referirse a todos los españoles que están por la democracia.

Deia contra la violencia. Es indiscutible su postura contraria a la acción violenta en el campo de la política. En todos sus editoriales está declarada con rotundidad esta postura: “...una vez más decimos, no a la violencia; a todas las violencias» 60 . Si examinamos esta cita es fácil interpretar que Deia con "violencia» se refiere a la de ETA, mientras que con "violencias" está dirigiéndose a otras violencias que acompañan a la de ETA y que son no menos condenables y hasta causa de la misma. Nunca aparecerá en Deia una condena que sea dirigida únicamente a ETA, que sea escueta, sin objeciones o matices. En algunas ocasiones hay que aclarar que la condena de la violencia va también contra ETA, como en el comunicado que un miembro del EBB, Joseba Azkárraga, hace con relación a la manifestación convocada por el PNV contra la violencia: «iHay que decir con todas nuestras fuerzas que también es contra ETA!»61.

Este evidente rechazo de Deia a la utilización de la violencia por parte de ETA está justificado por diferentes razones. Primeramente, su condena parte de un punto de vista moral y humano, de defensa de la vida como valor primordial. Este fundamento moral es claro cuando dice: “Ninguna muerte violenta puede legitimarse. Por encima de filiaciones políticas y de ideologías, de profesiones, clases sociales y lugares de nacimiento está la vida del hombre. De todo hombre. Esto no es una opción discutible, sino una exigencia de derecho natural. Nuestra sociedad debe recuperar, con urgencia, y antes que nada, la escala de valores éticos fundamentales, en que el derecho a la vida es el más importante. En su año de existencia Deia ha dejado claro testimonio de esta actitud..." ${ }^{62}$. También existen razones positivas de orden práctico. Odei Eureka, en el apartado de opinión Itzal-Argi (Luces y sombras), viene a decir que si se utiliza la violencia y se vulneran los principios básicos de la ética para la defensa de las reivindicaciones nacionalistas de Euskadi, no será posible reclamar una base en el Derecho y en los principios éticos, para estas mismas reclamaciones nacionalistas. Además, el sistema de libertades que pudiera conseguirse en Euskadi con la violencia sería un estado de pseudolibertad ${ }^{63}$. Por otra parte, desde una óptica de práctica política, la estrategia de la violencia de ETA es criticada desde Deia y el PNV reprochándole su falta de eficacia y su capacidad de entorpecer el avance en la consecución de los intereses del nacionalismo vasco. Así lo expresa el comunicado del EBB del PNV, publicado por Deia el 1 de diciembre de 1977 con motivo del asesinato del comandante de la Policia Armada de Pamplona, Joaquín Imaz, cuando dice que este partido "se de-

60 Editorial, "No a la violencia, a todas las violencias", Deia, 23-4-1978.

61 AzkARraga, J.: “Libertad y pacificación», Deia, 26-10-1978, p. 2.

62 Editorial, «Frente a la violencia, diálogo y libertad», Deia, 1-7-1978.

63 ODEl ERREKA: «Autismo», Deia, 1-7-1978. 
clara contrario a toda violencia y estima que la actitud de ETA representa un claro obstáculo para los objetivos autonómicos ${ }^{64}$.

Deia también razona su oposición a la estrategia de terror de ETA haciendo una reflexión serena de la situación política de la España de la Transición, en la que se han dado pasos importantes hacia una democracia plena. Acaban de celebrarse las elecciones libres del 15 de junio de 1977 y se está elaborando una constitución de consenso que será aprobada en referéndum en diciembre de este año 1978. «La situación actual —considera Deia- es radicalmente distinta. No hemos llegado a las cotas que deseamos para nuestro pueblo, pero se han conseguido objetivos importantes a través de los representantes elegidos democráticamente». El camino para alcanzar esas cotas, dirá luego, "es la negociación y el diálogo» ${ }^{65}$.

Con todo, a pesar de esa contundente negación de la violencia de ETA, porque es inhumana, porque es ineficaz en la lucha política, porque no tiene sentido politico en una situación de incipiente democracia, y a pesar de que en alguna ocasión carga la responsabilidad de las consecuencias de la violencia sobre ETA («...si por su causa retrocedemos en nuestro avance hacia una situación más democrática, el pueblo no se lo perdonará" $\left.{ }^{66}\right)$, a pesar de eso, no podemos pasar por alto en este análisis que Deia muestra una clara deferencia con los autores de la violencia a los que a veces considera verdaderos patriotas que se juegan la vida por Euskadi, llegando incluso a hacer semblanzas apologéticas de algunos de ellos. Recordaremos ahora, una vez más, las palabras que Deia pone en boca de Arzalluz: «Todavía hay vascos que mueren por su pueblo, a los que respetamos profundamente" y las afirmaciones de Ángel Cuerda, diputado del PNV por Álava: "...muchos de ellos hijos nuestros, hermanos o parientes [...] tienen en su lucha como nosotros, un ideal que contiene el mismo amor a nuestra patria vasca... ${ }^{67}$. Con motivo del asesinato de Argala, aparece en Deia el 22 de diciembre de 1978 un artículo sobre este dirigente de ETA que resulta ser un verdadero panegírico. De él se dice que era "sobrio, prudente e íntegro [...] Llevaba una vida de monje, sin salir de chiquiteo [...] persona íntegra y respetada en los ambientes abertzales... ${ }^{68}$.

En otras ocasiones, Deia hace un intento por atenuar la responsabilidad de los autores de la violencia, considerándolos víctimas de la estrategia errónea que han adoptado por culpa de actitudes ajenas de represión y violencia. Fue la vio-

64 Es conveniente recordar que por estas fechas el problema de la inclusión de Navarra en el ente preautónomico vasco está en su punto álgido. EI PNV en ese mismo comunicado denuncia la "ruin actitud de quienes aprovechan» estos atentados para enfrentar al pueblo navarro con el nacionalismo vasco.

65 Editorial, «El pueblo vasco no se lo perdonará», Deia, 7-3-1978.

66 lbidem. Podríamos entrever en esta cita una preocupación por una probable involución en estos momentos de la Transición.

67 Deia, 7-11-1978.

68 Deia, 22-12-1978. Este artículo no es de opinión y no está firmado. Pero es importante tenerio en cuenta para comprender cómo Deia condena la violencia de ETA, al tiempo que muestra una actitud de comprensión hacia los autores concretos de la violencia, hasta el punto de escribir un auténtico panegírico tras la muerte de uno de ellos. 
lencia que sufrió el pueblo vasco la que les empujó a coger las armas: «La violencia padecida engendró violentos. Euzkadi se consideró ocupada por fuerzas antivascas». Por otra parte, si mantienen la actividad violenta es porque Euskadi no consigue avanzar en la consecución de sus derechos y libertades: “El día que libre y democráticamente el País Vasco haya alcanzado esas cotas de autonomía, los grupos armados no tendrán ninguna razón de ser" ${ }^{69}$. Esta idea es la que le mueve a Marcos Vizcaya a declarar que "el PNV se compromete a pacificar Euzkadi en un año si se aceptan sus propuestas en la Constitución", o a Carlos Garaicoechea afirmar que si ellos - los nacionalistas del PNV - tuvieran el poder «la violencia hubiera quedado sin razón de existir entre nosotros».

Decíamos arriba que la no aceptación por Deia de la violencia de ETA era siempre matizada. Nunca se da una condena de la violencia dirigida solamente contra ETA. Siempre que se condena la violencia se hace con expresiones como "no es sólo contra ETA", "venga de donde venga", "de todas las violencias", "a la de uno y otro bando". El comunicado del PNV sobre la convocatoria de la manifestación contra la violencia, antes mencionada, dice: «Está claro [...] que la condena de la violencia y petición de que se abandone la lucha armada tiene que adjudicarse aquí y hoy, en una medida fundamental a ETA, aunque sea de justicia denunciar otras violencias, por desgracia existentes, y a veces resultantes de una larga trayectoria histórica "70. Cuando se condena a ETA habrá una condena contra la otras violencias: unas veces será la violencia de las Fuerzas de Orden Público que «no podemos menos de mirar [...] como el brazo armado que impone, por la fuerza, lo que no queremos aceptar»; otras veces es la violencia institucional por la que hay que protestar: "...no se puede condenar unilateralmente la violencia, sin que de algún modo se proteste enérgicamente por la violencia institucional que ha sufrido y sufre el pueblo vascos ${ }^{71}$; violencia institucional que, para el miembro del Euzkadi Buru Batzar, Joseba Azkarraga, «es tan importante como la anterior» (la violencia terrorista).

Para concluir, diremos que el difícil equilibrio del nacionalismo moderado en cuanto a la postura ante el terrorismo de ETA, queda perfectamente dibujado en Deia. El diario recoge esa situación que soporta el PNV que es, como dice Iñaki Anasagasti, la de estar solos ante un bando y otro: el mundo abertzale - también muchos de sus militantes ${ }^{72}$ - le reprocharán que condenar a ETA es ir contra la lucha por las libertades del pueblo vasco, es "hacer el juego" al centralismo antivasco; los otros, los no nacionalistas, le acusarán de que no condenar a ETA sin paliativos es carecer de sensibilidad democrática. La causa de esta situación está en la postura que hemos observado en Deia ante la violencia terrorista, que puede

69 Editorial, «Frente a la violencia, diálogo y libertad», Deia, 1-7-1978.

70 Deia, 28-10-1978, p. 14.

71 «Ante la manifestación antiterrorista», Deia, 12-10-1978, p. 12.

72 Ver Pérez-Nieva, S.: Modelo de partido y cambio político. El Partido Nacionalista Vasco en el proceso de la Transición y consolidación democrática en el País Vasco, Madrid, Peninsular, 2002. 
concretarse en un no claro a la violencia de ETA, pero acompañado siempre del no a otras violencias: la física (de las FOP) y la institucional (del Estado). Con esta inseparable negación de diferentes violencias, ese no a ETA queda matizado por una cierta justificación al insinuar que aquella violencia no existiría sin las otras dos.

\section{CONCLUSIÓN}

Según la clasificación del tratamiento periodístico del terrorismo que hemos seguido exclusivamente como metodología, el que sigue Deia no cabe en el denominado «tratamiento limitado", por lo que constatamos que Deia está favoreciendo a la organización terrorista con el modo de abordar el fenómeno de ETA, aunque no lo pretenda como se manifiesta en sus editoriales. El análisis que se ha realizado, nos descubre que la postura informativa de Deia favorece a ETA en los cinco puntos analizados:

1. No es veraz por considerar "lucha armada» lo que es «terrorismo»; «nobles patriotas» a los militantes de una organización que fríamente calcula la acción violenta dentro de estrategias estudiadas (acción-represión) y al dar un tratamiento más favorable a los militantes de ETA que a sus víctimas.

2. Dedica un espacio amplio y en lugares preeminentes a la organización ETA.

3. Sirve de atalaya a ETA para la difusión de ideas, opiniones, aclaraciones, amenazas, por medio de la publicación a menudo destacada de sus comunicados.

4. Utiliza el lenguaje propio de ETA, transmitiendo así el concepto que ETA tiene de su propia actividad. De esta manera ETA tiene en Deia un inestimable medio de difusión y propaganda de sus ideas.

5. En su línea editorial, la condena de la violencia de ETA puede convertirse en justificación, al matizarse siempre con la condena simultánea de otras violencias que pueden ser consideradas peores y causantes de la actividad violenta de ETA.

Por otra parte, comprobado que Deia comparte y publica las ideas y opiniones del mundo del nacionalismo moderado - cuyo referente es el PNV— no resulta arriesgado afirmar - aunque con cierta provisionalidad - que la postura que mantiene Deia en el momento histórico analizado ante el terrorismo de ETA es la misma que la de dicho partido. Al hilo de esta afirmación podemos aventurarnos a pensar que la razón de esta postura - ¿ambigua? - del Partido Nacionalista Vasco está en la ubicación sociopolítica en que se encuentra este partido. Al PNV le repele la acción violenta - siempre se ha declarado defensor de la vida y de los métodos democráticos- que además no cree que en estos momentos sea la estrategia más acertada para el logro de sus fines políticos. Pero negar a ETA es 
también negar al principal referente de la defensa de las reivindicaciones identitarias del nacionalismo vasco. El precio que el nacionalismo moderado ha de pagar por la negación frontal del terrorismo de ETA es muy alto: su desprestigio en el entorno más combativo del nacionalismo y su abandono en manos de la línea radical del mismo. Por eso, a medida que ETA va perdiendo su consideración de avanzadilla de la identidad vasca, la condena de ETA por parte del nacionalismo moderado es más decidida. Pero cabe preguntarse si esta actitud del nacionalismo vasco moderado favorable y complaciente - a su pesar-con ETA contribuyó a la creación de una opinión pública en la sociedad vasca, caracterizada por ser cuando menos comprensiva con la organización, que proporcionó fuerza y motivos a ETA para continuar y acrecentar su actividad terrorista. 